\title{
The processing of cataphora coreference in Brazilian Portuguese
}

\author{
Pablo Machel Nabot Silva de Almeida ${ }^{1}$, José Ferrari Neto ${ }^{2}$ \\ ${ }^{1}$ School of Humanities, GENP/LAPROL/GEPROL, Pontifical Catholic University of \\ Rio Grande do Sul, PUCRS, Brazil \\ 2Department of Portuguese Language and Linguistics, LAPROL/GEPROL, \\ Federal University of Paraíba, UFPB, Brazil \\ https://doi.org/10.36505/ExLing-2020/11/0020/000435
}

\begin{abstract}
This study aimed to explore whether the processing of cataphoric coreference in Brazilian Portuguese (BP) is guided by a top-down strategy as postulated by the active search mechanism (ASM) or by a bottom-up routine, as well as if this process is restricted by the Principle $C$ constraint. The results revealed that ASM is not a mechanism used to solve the intended coreference in BP and that the participants have demonstrated sensitiveness to establish the coreference while they had to interpret it. In addition, there is evidence that illicit antecedents are not considered during cataphoric resolution, which suggests that the Principle $C$ constraint impacts on the processing and seems to not be violated during the time course of the computation.
\end{abstract}

Key words: backwards anaphora, coreference, principle C, active search mechanism.

\section{Introduction}

Studies developed on the processing of backwards anaphora have shown that its computation is guided by an active search mechanism, henceforth ASM, which is driven by a top-down strategy without waiting for a bottom-up information to be analyzed. Moreover, the processing of cataphora only proceeds in structural positions that are not ruled out by the Principle $\mathrm{C}$ constraint (Chomsky, 1981). This type of computation has been provided by several studies conducted in different languages such as English (Kazanina et al., 2007). Additionally, concerning the impact of the Principle C constraint in $\mathrm{BP}$, the results that have been achieved are incipient and inconclusive (Lessa \& Maia, 2011; Maia, Garcia \& Oliveira, 2012).

Therefore, we raised the question whether the parser of a pro-drop partial null-subject language like Brazilian Portuguese (BP), which is in a process of parametric changing, would act in the same way as the parser of previously studied languages (see Barbosa, Duarte \& Kato, 2005). Hence, we aimed at investigating whether the processing of cataphoric coreference in BP is actually guided by the ASM or by a distinctive routine less active and if it is constrained by the action of the Principle $\mathrm{C}$ constraint.

ExLing 2020: Proceedings of 11 th International Conference of Experimental Linguistics, 12-14 October 2020, Athens, Greece 


\section{Methodology}

In order to clarify these open questions, we conducted a non-cumulative self-paced reading experiment that was run in the Language Processing Laboratory (LAPROL). Participants were 71 native speakers of BP from the Federal University of Paraíba (UFPB), and all of them gave informed consent and volunteered to participate. We employed the gender-mismatch paradigm (Van Gompel \& Liversedge, 2003) to conduct the experiment that was designed using the software Paradigm, version 2.5.0, in a laptop Acer Intel Core I5-2450M, 2,5 GHz, 4 GB DDR3. It had five conditions, four of which were organized in a $2 \times 2$ Latin Square design with the factors constraint (Principle C vs. No-Constraint) and gender congruency (Match vs. Mismatch between the pronoun and the subject of the second clause). An additional fifth control condition characterized by an anaphoric coreference was added. In each trial of the experiment an interpretative question was included to check if the participant identified if the coreference was established or not. A sample set of experimental items can be seen in example (1):

1. a. No-Constraint Match/No-Constraint Mismatch/Name Control

Visto que tempos atrás enquanto ela $a_{i}$ (Carlai) estava estudando para a seleção

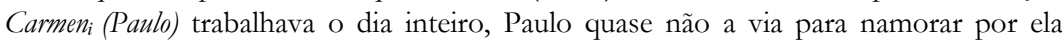
viver muito ocupada//Carla $\mathrm{a}_{\mathrm{i}}\left(\mathrm{el}_{\mathrm{i}}\right)$ prontificou-se a vê-lo para namorar nas horas vagas disponíveis para os dois. (a sample of the stimuli presented in BP).

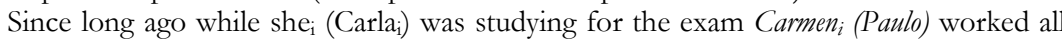
day, Paulo rarely saw her for dating because she was very busy//Carla $\mathrm{a}_{\mathrm{i}}$ (she $\mathrm{i}_{\mathrm{i}}$ volunteered to see him for a date in the spare time available to them.

\footnotetext{
b. Principle-C Match/Principle-C Mismatch Visto que tempos atrás ela $\mathrm{a}_{\mathrm{i}}\left(\mathrm{Carla}_{\mathrm{i}}\right)$ estava estudando para a seleção enquanto Carmen (Paulo) trabalhava o dia inteiro, Carla $\left(\mathrm{ela}_{\mathrm{i}}\right)$ se sentia constrangida por não contribuir também com as despesas. (a sample of the stimuli presented in BP). Since long ago she $\mathrm{i}_{\mathrm{i}}\left(\mathrm{Carla}_{\mathrm{i}}\right)$ was studying for the exam while Carmen (Paulo) worked all day, Carla $\mathrm{a}_{\mathrm{i}}\left(\mathrm{she}_{\mathrm{i}}\right)$ felt embarrassed for not also contributing to expenses.
}

For the analysis of the reading-time data, the critical segment concerning the first NP that was taken as the first potential postcedent ${ }^{1}$ was analyzed. Also, the interpretative questions were analyzed as well. The $\mathrm{R}$ lme4 package (Bates, Maechler, Bolker \& Walker, 2015) was used for the analysis and linear mixed-effects regressions were calculated for each condition of interest.

\section{Results and discussion}

After removing outliers from the data, which resulted in an approximately normal distribution of the data, a linear mixed-effect model was used, adopting the reaction times (RT) from the reading of the critical segment as dependent variable and both subjects and items as random effects. Type of principle 
(Principle-C and No-Constraint) and Matching (Match and Mismatch) were considered as independent variables. The results of the statistical analysis are shown in Table 1:

Table 1. Results of the linear mixed-effect model statistics.

\begin{tabular}{lccccl}
\hline & Estimate & Std.Error & df & t-value & $\operatorname{Pr}(>|\mathrm{t}|)$ \\
& & & & & \\
\hline (Intercept) & 970.56 & 35.84 & 81.17 & 27.079 & $<2 \mathrm{e}-16^{*}$ \\
PrincipleCNoConstraint & -142.54 & 25.60 & 181.14 & -5.569 & $9.15 \mathrm{e}-08^{*}$ \\
MatchMismatch & -41.67 & 23.02 & 818.11 & -1.811 & 0.0706 \\
$\quad \begin{array}{l}\text { PrincipleCNoConstraint : } \\
\text { MatchMismatch }\end{array}$ & 40.38 & 31.97 & 1444.15 & 1.263 & 0.2067 \\
\hline
\end{tabular}

The lack of a gender-mismatch effect (GMME) emerged in the pairwise comparison between the No-constraint conditions, suggesting that the processing of backwards anaphora in BP is not driven by an active and top-down routine resembling the ASM as predicted $(\mathrm{t}(70)=35.24, \mathrm{p}<0.5)$. Furthermore, the lack of significant differences between Match and Mismatch conditions reveal that the phi-feature of gender does not influence that kind of processing regardless of the active presence of the Principle $C$ constraint. On the other hand, the significant differences revealed in the comparisons made between Principle $\mathrm{C}$ and No-Constraint conditions show that the Principle C constraint interferes in the processing of cataphoric coreference as well as longer reading times observed in the No-Constraint conditions illustrate that the processing of cataphora is harder when there is no Principle- $\mathrm{C}$ constraint operating in the referred coreferential processing.

The responses given by the subjects to the interpretation of the coreference, here also considered as a dependent variable, were analyzed by using a chisquare test $\left(\mathrm{X}^{2}\right)$. The results are shown in Tables 2 and 3 below:

Table 2. Results of the chi-square test $\left(\mathrm{X}^{2}\right)$ : gender.

\begin{tabular}{cccc}
\hline & Match & Mismatch & Total \\
\hline Expected & 514 & 467 & 981 \\
Unexpected & 338 & 385 & 723 \\
Total & 852 & 852 & 1704 \\
\hline
\end{tabular}

$\mathrm{X}^{2}=5,08$, D.F $=1, \mathrm{p}<0.02$.

Table 3. Results of the chi-square test $\left(\mathrm{X}^{2}\right)$ : constraint.

\begin{tabular}{cccc}
\hline & Principle-C & No-Constraint & Total \\
\hline Expected & 444 & 537 & 981 \\
Unexpected & 408 & 315 & 723 \\
Total & 852 & 852 & 1704 \\
\hline
\end{tabular}

$\mathrm{X}^{2}=20,335$, D.F $=1, \mathrm{p}<0.05$. 
In relation to the interpretation of cataphoric coreference, the results point out that BP speakers find it easier to correctly establish the coreference when there is no constraint, whereas they hesitate to reject the coreference and establish the appropriate disjoint reference when the Principle $\mathrm{C}$ constraint operates. Finally, although in both Match and Mismatch conditions BP speakers have demonstrated to be able to correctly establish the expected coreference, the results demonstrate that the answers were more consistent in the Match conditions. This pattern signals the phi-feature of gender is also able to modulate the interpretation of cataphoric coreference, even though it is not able to influence it in the earlier processing phase. In sum, this suggests that the morphological congruence makes it easier for BP speakers to accept the suitable coreference as opposed to the morphological incongruence that makes harder such a coreferential interpretation towards the proper disjoint reference.

\section{Notes}

1. See Almeida (2016) for the original use of the term poscedente (postcedent) in BP.

\section{Acknowledgements}

We thank to CAPES - Financing Code 001 and to CNPq - Project 870599/1997 6, concerning Process 140275/2019 3. We also are grateful to Lilian Cristine Hübner for her revision and constructive comments.

\section{References}

Almeida, P. M. N. S. D. 2016. O Processamento da correferência catafórica pronominal pessoal em Português Brasileiro. Master's thesis, Federal University of Paraíba UFPB, João Pessoa.

Barbosa, P., Duarte, M. E. L., Kato, M. A. 2005. Null subjects in European and Brazilian Portuguese. Journal of Portuguese Linguistics 4(2), 11-52.

Bates, D., Maechler, M., Bolker, B., Walker, S. 2015. Fitting linear mixed-effects models using lme4. Journal of Statistical Software 67(1), 1-48.

Chomsky, N. 1981. Lectures on Government and Binding. Dordrecht, Foris.

Kazanina, N., Lau, E. F., Lieberman, M., Yoshida, M., Phillips, C. 2007. The effect of syntactic constraints on the processing of backwards anaphora. Journal of Memory and Language 56(3), 384-409.

Lessa, P. D. C., Maia, M. 2011. O processamento da correferência de expressões-R com restrições lexicais em Português Brasileiro. In Brazilian Linguistics Association (ed.), Proc. $7^{\text {th }}$ Abralin International Congress, 3598-3606, Curitiba, Brazil.

Maia, M., Garcia, D. C. D., Oliveira, C. D. 2012. The processing of conceptual anaphors and fully specified pronouns in intra-sentential contexts in Brazilian Portuguese. ReVel: Revista Virtual de Estudos da Linguagem 10(6), 200-219.

Van Gompel, R. P. G., Liversedge, S. P. 2003. The influence of morphological information on cataphoric pronoun assignment. Journal of Experimental Psychology: Learning, Memory, and Cognition 29(1), 128-139. 